\title{
Cauda equina syndrome associated with multiple lumbar arachnoid cysts in ankylosing spondylitis: improvement following surgical therapy
}

\author{
Pamela J Shaw, David A Allcutt, David Bates, Peter J Crawford
}

\begin{abstract}
A case of cauda equina syndrome with multiple lumbar arachnoid cysts complicating ankylosing spondylitis (AS) is described. The value of computerised tomography (CT) and magnetic resonance imaging (MRI) as a non-invasive means of establishing the diagnosis is emphasised. In contrast to previously reported cases the patient showed neurological improvement following surgical therapy. Surgery may be indicated in some patients, particularly when there is nerve root compression by the arachnoid cysts and when the patient is seen early before irreversible damage to the cauda equina has occurred.
\end{abstract}

Ankylosing spondylitis (AS) is a chronic inflammatory disease of unknown cause, which affects primarily the axial joints of the vertebral column, but which may be associated with peripheral arthritis and various non-skeletal manifestations including cardiovascular or pleuropulmonary involvement, uveitis, amyloidosis and neurological complications.

Neurological complications of AS were first described in 1893 by von Bechterew. ${ }^{1}$ Recognised neurological disorders include isolated dorsal or lumbo-sacral nerve root lesions which typically develop when the disease is active, produce pain without significant neurological deficit, and usually resolves spontaneously. $^{2}$ Atlanto-axial subluxation with secondary spinal cord compression occasionally occurs ${ }^{3}$ and damage to the cervical or thoracic cord may follow relatively minor trauma in AS because the ankylosis and osteoporosis of the spine render it brittle and unduly susceptible to injury. ${ }^{4}$ Occasional patients have been described who have developed intraspinal sarcoma as a complication of radiation therapy for AS. ${ }^{5}$

The occurrence of a cauda equina syndrome complicating AS was first described by Bowie and Glasgow in 1961.6 Since then the association has been confirmed in a number of additional reports. ${ }^{7-31}$ In the majority of cases described there is dilatation of the lumbar theca with multiple posterior arachnoid diverticula eroding the laminae and spinous processes in the lumbo-sacral region. These cases have usually been investigated by myelography, a procedure which may be technically difficult in AS and which may also result in neurological deterioration in patients with the cauda equina syndrome. ${ }^{25}$ Most authors have concluded that the management of these patients should be conservative and that no benefit has resulted from any form of treatment tried including steroids, non-steroidal anti-inflammatory drugs and surgical exploration or decompressive laminectomy. ${ }^{7812} 131725$

We report a case of cauda equina syndrome in AS to emphasise: 1) The role of computerised tomography (CT) and magnetic resonance imaging (MRI) of the spine as a noninvasive means of making the diagnosis; 2) The potential benefit of surgical therapy.

\section{Case report}

A 68 year old retired veterinary surgeon presented with a two year history of progressive neurological symptoms. Initially he developed numbness of the sole of the right foot which gradually extended to involve the lateral aspect of the foot and lower leg. He had noticed progressive wasting of the muscles of the right calf, posterior thigh and buttock, had developed a limping gait and was unable to bear weight on his right foot. He had continuous dull aching pain in the lumbar spine which radiated down the posterior aspect of both thighs. In addition he suffered episodic lancinating pain over the lateral aspect of the right foot. This particularly occurred just before or at the onset of micturition or defaecation, tended to be relieved by recumbency, and was not affected by coughing or spinal movement. In the previous six months he had become impotent and had developed urgency of micturition together with hesitancy and intermittency of the urinary stream. He had also developed difficulty with defaecation and involuntary faecal soiling. In his previous history he had developed ankylosing spondylitis at the age of 23 years. This had been treated with spinal irradiation in 1946. His rheumatological symptoms had been quiescent for many years before the onset of his neurological complaints.

On examination he had restricted chest expansion and gross limitation of all spinal movements in keeping with the ankylosing spondylitis. Straight leg raising was possible to 90 degrees bilaterally. He had a limping gait with a partial right-sided foot-drop. The cranial nerves, fundi and upper limbs were normal. There was marked wasting of the gluteal, posterior thigh and calf muscles and weakness of hip extension (MRC grade 4/5), 
Figure A.CT scan through the L4 vertebra showing marked bilocular pressure erosion of the right lamina. B. MRI scan in the sagittal plane showing multiple areas of smooth, scalloped erosion of the posterior elements of the spinal canal from $L 2$ to L5.

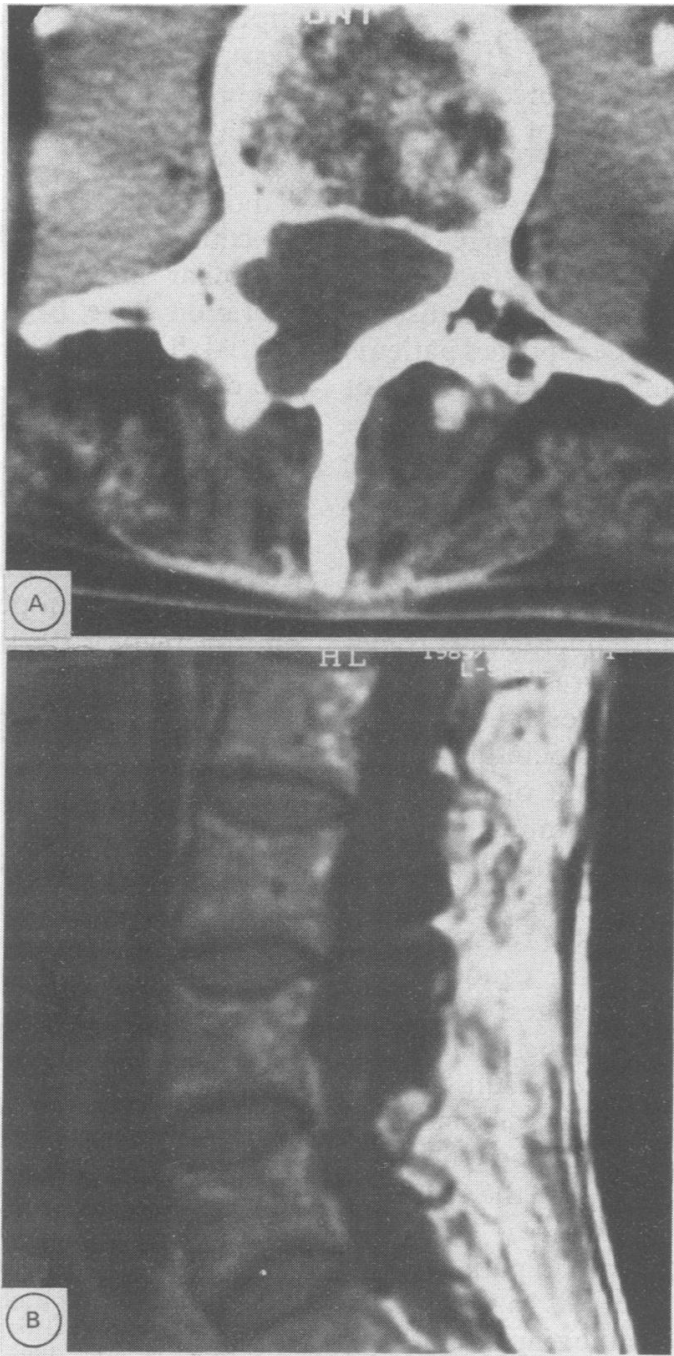

fluid (CSF), showed no enhancement with gadolinium and was considered most likely to represent a multiloculated arachnoid cyst (fig B).

\section{Subsequent course}

Surgical exploration was undertaken with laminectomy from L3 to L5. Inflammatory tissue was present in the paraspinal regions and all the spinal ligaments were calcified. Several large thin-walled arachnoid cysts were found eroding into the vertebral arch of the lumbar vertebrae and communicating directly with a voluminous lumbar theca. The L5, S1 and S2 roots appeared compressed on the right side. The cysts were marsupialised so that there was wide communication with the lumbar theca and the epidural space.

Histological examination of an excised fragment of one of the cysts showed both dura and arachnoid matter with chronic inflammatory changes, vascularisation and haemosiderin pigment deposition. Throughout there was an accumulation of amorphous granular material in macrophages which showed the staining characteristics of haemosiderin.

Two months post-operatively the patient reported that many of his symptoms had improved. In particular bowel and bladder function had returned to normal and his pain had almost completely resolved. There had been some reduction in the area of numbness in the right leg. There was some improvement in the power of the right gluteus maximus and hamstring muscles though the distal weakness and wasting showed no objective change.

\section{Discussion}

knee flexion (4/5), ankle dorsiflexion $(4+/ 5)$, plantar flexion $(4-/ 5)$, inversion $(4-/ 5)$, eversion $(4-/ 5)$ and extensor hallucis longus $(4 / 5)$ in the right lower limb. The left leg was of normal appearance and power. The right knee jerk was depressed compared to the left, both ankle jerks were absent and the right plantar response was absent while the left was flexor. In the right leg light touch and pinprick sensation were impaired over the L5, S1 and S2 dermatomes and vibration sense was impaired at the ankle. Anal tone was reduced and the anal reflex was absent.

\section{Investigations}

Routine haematological and biochemical screening investigations were normal apart from a mildly elevated ESR at $25 \mathrm{~mm} /$ hour. Spinal and pelvic radiographs showed appearances typical of ankylosing spondylitis. CT scan of the lumbar spine showed marked widening of the spinal canal with evidence of pressure erosion of the right laminae of $\mathrm{L} 4$ and L5. No separate mass lesion was seen and the appearances suggested dural ectasia (fig A). MRI scan of the same area showed an expansile lesion between L2 and L5 causing smooth scalloped erosion of the right posterolateral and posterior aspects of the canal. The material had signal characteristics identical to cerebrospinal
The cauda equina syndrome in AS is imperfectly understood. Typically it develops many years after the onset of the spondylitis when the rheumatological symptoms are quiescent. ${ }^{25}$ The L5 and sacral roots tend to be selectively involved. Sensory and sphincter complaints occur early, pain is often prominent, and motor deficits are less frequent. ${ }^{25} 32$ The association between the cauda equina syndrome in AS and posteriorly projecting diverticula from the lumbo-sacral canal was first recognised by Matthews and is now regarded as a characteristic feature of the syndrome. ${ }^{10}$ While the myelographic picture of the cauda equina syndrome is distinctive, there appears to be considerable variation in the macroscopic and histological appearances. Some authors have described fibrosis and chronic arachnoiditis embedding atrophic lumbo-sacral roots. ${ }^{72}$ Lee and Waters described small sacral roots splayed out and adherent to the dura. ${ }^{8}$ Others have found no evidence of arachnoiditis. Matthews in a well-described necropsy study found diverticula lined by periosteum and dura. No inflammatory process was evident in the meninges or eroded vertebrae and the cauda equina was not compressed or involved in arachnoid adhesions. Some of the nerve roots showed fibrosis and loss of myelin. ${ }^{10}$

The pathogenesis of cauda equina damage in AS is not known. Direct compression of the 
nerve roots by the arachnoid cysts which occurred in our patient and in two other reported cases ${ }^{18} 28$ appears to be uncommon and the bony ankylosis in AS does not encroach on the intervertebral foramina. ${ }^{1015}$ Radiation therapy has been considered as a possible cause of inflammatory cauda equina damage. While the role of radiotherapy cannot be completely discounted, it clearly is not the only predisposing factor as at least half of the reported patients with AS and cauda equina syndrome have not been subjected to spinal irradiation. ${ }^{25}$ In some cases of AS the spinal meninges are undoubtedly involved in the inflammatory process attacking the vertebral column and this may result in chronic arachnoiditis. Adhesions may result in the formation of arachnoid pouches that expand under pressure fluctuations transmitted to the lumbar sac as a result of respiration and arterial pulsation. Possible mechanisms for nerve root damage include: inflammatory injury as a direct result of the arachnoiditis; gravitational traction injury resulting from the presence of the arachnoid cysts; or traumatic damage from excessive intra-spinal pressure fluctuations caused by reduced elasticity and compliance of the caudal theca exposed to inflammatory changes. Whatever the exact mechanism the nerve root damage appears to occur as a late result of the mechanical effects of previous inflammation.

In most previously reported cases the diagnosis has been established on the basis of typical myelographic appearances. However, this procedure may be difficult in patients with AS, as the fixed dorsal kyphosis may interfere with positioning on the radiograph table and the bony ankylosis and calcification of spinal ligaments may make lumbar puncture difficult. Also some patients show neurological deterioration following myelography. ${ }^{25}$ Our patient illustrates the value of CT and MRI imaging in demonstrating the characteristic pathology in the lower spinal canal. We suggest that these should be the investigations of choice in AS and that myelography should be avoided if possible.

A review of the literature has shown that spinal surgery has been undertaken in only a small number of patients and has usually been considered to produce no improvement in the cauda equina deficit. Of eight previously reported patients who had laminectomy, two were transiently worse after the procedure, ${ }^{1625} \mathrm{six}$ showed no benefit ${ }^{78122228}$ and one of the latter group developed postoperative meningomyelitis and died. ${ }^{22}$ However, in these cases surgical exploration was underaken late, when severe and prolonged damage to the cauda equina had already occurred. It is possible that early exploration and decompression of the arachnoid diverticula may give a better result. The case that we report had considerable improvement in his quality of life after laminectomy and marsupialisation of the arachnoid cysts. He became pain-free, regained normal control of bowel and bladder function, and noticed improvement in his gait. Longer follow up will be required to determine whether the residual neurological signs will show further improvement. We recommend that surgical therapy should be considered in those cases where radicular pain is intrusive or where sphincter control or mobility are threatened, particularly if nerve root compression can be demonstrated and if the patient is seen early in the course of the cauda equina syndrome.

Similar arguments regarding the role of operation have been applied to spinal perineurial (Tarlov) cysts. ${ }^{33}$ These cysts arise at the site of the posterior root ganglion usually on sacral roots. They may be asymptomatic but can also produce compression of the surrounding cauda equina roots. Surgery has been recommended when disabling symptoms and signs can be clearly attributed to the cysts. In this situation postoperative cure or substantial improvement is the usual result..$^{33}$

We thank Dr Paul G Ince, consültant neuropathologist, Newcastle General Hospital, who reported the histological finding in this case and gave helpful comments and advice.

1 Von Bechterew W. Steifigkeit der Wirbelsaule und ihre verkrummung als besondere Erkrankungsform. Neurol Centralblatt 1893;12:426-34.

2 Forestier J, Jacqueline F, Rottes-Querol J. Ankylosing spondylitis. Springfield, Illinois: Thomas, 1956.

3 Martel W, Page JW. Cervical vertebral erosions and subluxations in rheumatoid arthritis and ankylosing spondylitis. Arthritis and Rheumatology 1960;3:546-56.

4 Weinstein PR, Karpman RR, Gall EP, Pitt M. Spinal cord injury, spinal fracture and spinal stenosis in ankylosing spondylitis. $J$ Neurosurg 1982;57:609-16.

5 Edgar MA, Robinson MP. Post-radiation sarcoma in ankylosing spondylitis. A report of 5 cases. J Bone Joint Surg 1973;55:183-8.

6 Bowie EA, Glasgow GL. Cauda equina lesions associated with ankylosing spondylitis: report of three cases. $\mathrm{Br} \mathrm{Med}$ $J 1961 ; 2: 24-7$.

7 Hauge T. Chronic rheumatoid polyarthritis and spondylarthritis associated with neurological symptoms and signs occasionally simulating an intraspinal expansive process. Acta Chir Scand 1961;120:395-401.

8 Lee MLH, Waters DJ. Neurological complications of ankylosing spondylitis. Br Med J 1962;1:798.

9 McGill IG. An unusual neurological syndrome associated with ankylosing spondylitis. Guys Hosp Rep 1966;115: 33-6.

10 Matthews WB. The neurological complications of ankylosing spondylitis. J Neurol Sci 1968;6:561-73.

11 Rosenkranz W. Ankylosing spondylitis: cauda equina syndrome with multiple spinal arachnoid cysts. J Neurosurg 1971;34:241-3.

12 Gordon AL, Yudell A. Cauda equina lesion associated with rheumatoid spondylitis. Ann Intern Med 1973;78:555-7.

13 Russel ML, Gordon DA, Ogryzlo MA, McPhedran RS. The cauda equina syndrome of ankylosing spondylitis. Ann cauda equina syndrome of
Intern Med 1973;78:551-4.

14 Matthews WB. Cauda equina syndrome in ankylosing spondylitis. Br Med J 1974;1:517.

15 Thomas DJ, Kendall MJ, Whitfield AGW. Nervous system involvement in ankylosing spondylitis. $\mathrm{Br}$ Med 1974;1:148-50.

16 Auquier L, Siaud JR, Guiot G, Lhermitte F. Syndrome de la queue de cheval au cours de la spondylarthrite ankylosante: découverte opératoire d'une fusion entre vertèbre et dure-mère dans la cas rapporté. Rev Rhum Mal Osteoartic 1974;41:733-7.

17 Hassan I. Cauda equina syndrome in ankylosing spondylitis: report of six cases. J Neurol Neurosurg Psychiatry 1976;39:1172-8.

18 Milde EJ, Aarli J, Larsen JL. Cauda equina lesions in ankylosing spondylitis. Scand J Rheumatol 1977;6: ankylosing

19 Cumming WJK, Saunders M. Radiculopathy as a complication of ankylosing spondylitis. J Neurol Neurosurg Psytion of ankylosing spondy
chiatry 1978;41:569-70.

20 Kramer LD, Krouth GJ. Computerised tomography: an adjunct to early diagnosis in the cauda equina syndrome of ankylosing spondylitis. Arch Neurol 1978;35:116-18.

21 Gabay R, Guignard D, Chantraine A. A rare extra-articular manifestation of ankylosing spondylitis: cauda equina syndrome. $J$ Rheumatol 1978;5:234-5.

22 Soeur M, Monseu G, Baleriaux-Waha D, et al. Cauda equina syndrome in ankylosing spondylitis. Anatomical diagnostic and therapeutic considerations. Acta Neurochir 1981;55:303-15.

23 Young A, Dixon A, Getty J, et al. Cauda equina syndrome complicating ankylosing spondylitis: use of electromyography and computerised tomography in diagnosis. Ann Rheum Dis 1981;40:317-22.

24 Contamin F, Doubrere JF, Struz PH, Baillet P. Sur 
l'association spondylarthrite ankylosante syndrome de la queue de cheval et dilatation du cul-de-sac avec volumineux diverticule arachnoidien. Etude clinique, radiologique et tomodensitométrique d'un cas. Sem Hop Paris 1983;59:1401-4.

25 Bartleson JD, Cohen MD, Harrington TM, Goldstein NP Ginsburg WW. Cauda equina syndrome secondary to long-standing ankylosing spondylitis. Ann Neurol long-standing

26 Grosman H, Gray R, St Louis EL. CT of long-standing ankylosing spondylitis with cauda equina syndrome. AJNR 1983;4:1077-80.

27 Tilgner M, Fortin D. Ankylosing spondylitis with cauda equina syndrome. Case report. Mo Med 1985;82:708-10.

28 Byrne E, McNeill P, Gilford E, Wright C. Intradural cyst with compression of the cauda equina in ankylosing spondylitis. Surg Neurol 1985;23:162-4.

29 Devlin GP, Sheppeard H. Cauda equina syndrome in ankylosing spondylitis diagnosed by computed tomography. NZ Med J 1987;100:651-2.

30 Travis RC, Byrne $P$. The cauda equina syndrome: a rare extra-articular manifestation of ankylosing spondylitis-a case report. Australas Radiol 1987;31:395-6.

31 Rubenstein DJ, Ghelman B. Cauda equina syndrome complicating long-standing ankylosing spondylitis. Skeletal

32 Whitfield AGW. Neurological complications of ankylosing spondylitis. In: Vinken PJ, Bruyn PW, eds. Handbook of clinical neurology Vol 38. Amsterdam: Elsevier, North Holland Biomedical Press, 1979:505-20.

33 Tarlov IM. Spinal perineurial and meningeal cysts. J Neurol Neurosurg Psychiatry 1970;33:833-43. 